\title{
ФОСФОРИЛИРОВАННЫЕ
}

ПОЛИПРЕНОЛЫ - НОВЫЙ

КЛАСС СОЕДИНЕНИЙ

С ПРОТИВОВОСПАЛИТЕЛЬНОЙ

И БРОНХОЛИТИЧЕСКОЙ АКТИВНОСТЬЮ

\author{
А.В. Санин ${ }^{1}$, И.В. Ганшина ${ }^{1}$, Г.Ф. Судьина ${ }^{2}$, В.Ю. Санина ${ }^{1}$, \\ Т.Н. Кожевникова ${ }^{1}$, А.В. Пронин ${ }^{1}$, А.Н. Наровлянский ${ }^{1}$, \\ С.А. Суханова ${ }^{3}$, О.В. Проскурина ${ }^{3}$, Н.М. Митрохин ${ }^{3}$ \\ ${ }^{1}$ ФГБУ НИИ эпидемиологии и микробиологии им. Н.Ф. Гамалеи Минздравсоиразвития РФ, Москва \\ ${ }^{2}$ НИИ физико-химической биологии МГУ им. Белозерского, Москва \\ ${ }^{3} \mathrm{OАО}$ «ВНЦ БАВ», Купавна
}

Резюме. Фосфорилированные полипренолы (ФП), выделенные из различных растительных источников, обладают доказанной иммуномодулирующей и противовирусной активностью. В настоящей статье отражены результаты изучения наличия и степени выраженности противовоспалительной активности у ФП на модели ингибиции активности 5-липоксигеназы (5-ЛПГ) и 15-липоксигеназы (15-ЛПГ), и на моделях отеков лапы крысы, индуцированных каррагинаном или полным адъювантом Фрейнда (ПАФ). Также изучали бронхолитическую активность ФП на моделях гистамин-, ацетилхолин- и антигениндуцированной контрактуры гладких мышц изолированной трахеи морской свинки. Установлено, что ФП оказывал дозозависимое ингибирующее воздействие на активность 5-ЛПГ и 15-ЛПГ. В суспензионной культуре нейтрофилов достоверное подавление образования продуктов 5-ЛПГ - лейкотриенов отмечалось при концентрации уже 5 мкг/мл; при концентрации 100 мкг/мл активность фермента подавлялась практически полностью. В клетках, культивируемых на коллагеновой подложке, достоверный ингибирующий эффект также отмечали при концентрации ФП 5 мкг/мл; при концентрации 20 мкг/мл активность 5-ЛПГ снижалась примерно в 20 раз. При изучении воздействия ФП на активность 15-ЛПГ было установлено, что при концентрации 80 мкг/мл активность фермента падала в 2 раза. Увеличение концентрации ППФ до 250 мкг/мл приводило к 5-кратному угнетению активности 15-ЛПГ. Таким образом, ФП растительного происхождения являются активными ингибиторами обеих липоксигеназ. На моделях каррагинан- и ПАФ-индуцированного отека лапы крыс установлено, что ФП в дозах 2-10 мг/кг обладают противовоспалительной активностью, хотя и менее выраженной, чем индометацин. Показано также, что ФП проявляют бронхолитическую активность на моделях бронхоспазма in vitro на морских свинках. С учетом ранее полученных данных, свидетельствующих о том, что ФП могут функционировать как контррегуляторы MIF (фактора ингибиции миграции макрофагов), важнейшего провоспалительного цитокина, делается заключение о наличии у ФП противовоспалительных и бронхолитических свойств, что может быть использовано при разработке новых препаратов для профилактики и лечения бронхиальной астмы, воспалительных заболеваний и иных патологических состояний.

Ключевые слова: фосфорилированные полипренолы, липоксигеназа, противовоспалительная активность, бронхолитическая активность.

поступила в редакцию 25.05.2011 принята к печати 28.06.2011

() Санин А.В. и соавт., 2011

\footnotetext{
Адрес для переписки:

Санин Александр Владимирович, д.б.н., профессор, зав. лабораторией клеточного иммунитета ФГБУ НИИЭМ им. Н.Ф. Гамалеи Минздравсоцразвития
} 


\section{PHOSPHORILATED POLYPRENOLS - A NOVEL CLASS OF COMPOUNDS WITH ANTI-INFLAMMATORY AND BRONCHIAL SPASMOLYTIC ACTIVITY}

Sanin A.V., Ganshina I.V., Sudiyna G.F., Sanina V.Yu., Kozhevnikova T.N., Pronin A.V., Narovlyanskiy A.N., Sukhanova S.A., Proskurina O.V., Mitrokhin N.M.

Abstract. Phosphorilated polyprenols (PP) isolated from different sources are known to exert immunomodulating and antiviral activities. In this paper possible anti-inflammatory action of PP were studied using sensitive models of 5-lypoxigenase and 15-lypoxigenase activity inhibition, as well as a model of the hypostasis induced by the complete Freundt's adjuvant, or carraginan. Also in vitro model of bronchospasm was used to study prospective broncholytic activity of PP. The latter was found to exert dose-dependent inhibitory effect upon both 5-lypoxigenase and 15-lypoxigenase activity. In the suspension cell culture significant inhibitory effect of PP upon leukotriens production was found even at a concentration of $5 \mathrm{mcg} / \mathrm{ml}$; at concentration of $100 \mathrm{mkg} / \mathrm{ml}$ activity of the enzyme was suppressed almost to zero. In neutrophil cells cultivated on a collagenic substrate the significant inhibitory effect was also found at the concentration of $5 \mathrm{mcg} / \mathrm{ml} ; 20 \mathrm{mcg} / \mathrm{ml}$ of PP reduced 5-LOX activity approximately 20fold. In another protocol PP significantly inhibited 15-LOX activity. Thus, PP may be regarded as active inhibitor of both lipoxygenases. The PP exerted anti-inflammatory activity at both models of hypostasis, though it was weaker compared with indomethacin. Also PP was found to possess broncholytic activity in vitro in the bronchospasm model. Taking into account early established findings proving that PP may function as a physiological counterregulator of MIF (macrophage inhibitory factor), a major pro-inflammatory cytokine, our data prove that PP possess antiinflammatory and broncholytic activities, which might be used for development of novel drugs for preventive care and treatment of bronchial asthma, inflammatory diseases and other pathologies. (Infekc. immun., 2011, vol. 1, N 4, p. 355-360)

Key words: phosphorilated polyprenols, lypoxigenase, anti-inflammatory action, broncholytic activities.

\section{Введение}

В основе терапии воспалительных процессов лежит фармакологическая коррекция воспалительной реакции организма. Используемые для этой цели противовоспалительные препараты стероидного и нестероидного происхождения, как правило, обладают различным побочным действием, в связи с чем их применение представляется не всегда эффективным и недостаточно безопасным. Это обусловливает поиск перспективных противовоспалительных средств растительного происхождения, которые могут быть лишены подобных недостатков. Имеются данные о наличии противовоспалительной активности у ряда экстрактов, полученных из растений Сибири [3].

В настоящей работе изучали возможные противовоспалительные свойства фосфорилированных полипренолов (ФП), выделенных из хвои сибирской сосны. Ранее было показано, что ФП, полученные из различных растительных источников, обладают иммуномодулирующей и противовирусной активностью, что нашло отражение при разработке и внедрении в практическую ветеринарную медицину таких препаратов, как фоспренил и гамапрен [5]. В статье приводятся данные о наличии и степени выраженности противовоспалительных и бронхолитических свойств у ФП, полученные на нескольких моделях:

- по степени ингибиции активности ферментов 5-липоксигеназы и 15-липоксигеназы;

- при изучении отеков лапы крысы, индуцированных каррагинаном или полным адъювантом Фрейнда (ПАФ);
- при исследовании бронхолитической активности in vitro на моделях гистамин-, ацетилхолин- и антиген-индуцированной контрактуры гладких мышц изолированной трахеи морской свинки.

\section{Материалы и методы}

В качестве источника ФП использовали препарат Фоспренил производства ЗАО «Микроплюс», содержавший 4 мг полипренилфосфата натрия в 1 мл.

Тестирование активности 5-ЛПГ проводили с помощью количественной оценки продуктов реакции - лейкотриена B4 (LTB4), 5-гидроксиэйкозатетраеновой кислоты (5-HETE), рокси- и (iso-LTB4) в водно-метанольных экстрактах культивируемых клеток. Полиморфноядерные лейкоциты выделяли из свежеполученной донорской крови с помощью двухслойного градиента Ficoll-Paque, культивировали в виде суспензии или на коллагеновых подложках. ФП добавляли в культуру за 30 мин до индуктора синтеза лейкотриенов. В качестве активирующего агента использовали кальциевый ионофор А23187. Водно-метанольные экстракты культивируемых клеток очищали твердофазной экстракцией на картриджах C18Sep-Pak и анализировали методом жидкостной хроматографии под повышенным давлением (HPLC). Продукты реакции идентифицировали ко-элюцией с использованием стандартных растворов вышеназванных веществ.

Оценку активности 15-ЛПГ из соевых бобов (Sigma) с использованием в качестве субстрата 
линолевой кислоты (Sigma) проводили по методу A. Simon et al. [8]. Для удаления возможных антиоксидантных примесей линолевую кислоту очищали на колонке Mallinkrodt, заполненной силикагелем AR CC-4. Активность 15-ЛПГ определяли путем измерения поглощения кислорода с помощью кислородного электрода Кларка (оксиграф Gilson), исходя из кислородной концентрации 20 мкМ в насыщенном воздухом буфере при $25^{\circ} \mathrm{C}$. Стандартная смесь реагентов содержала 5-ЛПГ картофеля в 0,2 М натриево-ацетатном буфере (pH 5,6), или 5'-, 8'-, 15'-ЛПГ из Lupinus albus в 66 мМ фосфатном буфере (pH 6,0), или 15-ЛПГ из соевых бобов в 0,25 мМ тетраборатном буфере (pH 9,0). Реакцию начинали добавлением 66 мкМ линолевой кислоты при варьировании концентрации энзима до достижения максимальной скорости реакции, при соблюдении условии насыщения Михаэлиса.

При воспроизводстве модели каррагинан-индуцированного отека лапы крыс в правую лапу крысы субплантарно вводили $1 \%$ раствор каррагинана (SERVA) в объеме 0,1 мл. ФП в дозах 2, 4, 10 мг/кг вводили внутрибрюшинно за 30 мин до введения каррагинана, препарат сравнения индометацин (Балканфарма) в дозе 10 мг/кг применяли внутрижелудочно за 60 мин до инъекции каррагинана. Измерение объема лап проводили с помощью цифрового водяного плетизмометра (Ugo Basel) через 4 часа после введения каррагинана. Терапевтическое воздействие вещества оценивали по степени угнетения воспалительной реакции в сравнении с интактной левой лапой данного животного и реакцией лап крыс контрольной группы.

При воспроизводстве модели ПАФ-индуцированного отека лапы крыс, ПАФ (SERVA) вводили субплантарно в правую лапу крысы в объеме 0,1 мл. ФП в дозах 2, 4 и 10 мг/кг вводили в/б за 30 мин до введения ПАФ и через 1 ч после введения. Препарат сравнения индометацин в дозе 10 мг/кг применяли внутрижелудочно за 1 ч до введения ПАФ и через 1 ч после введения.

Для создания модели гистамин-, ацетилхолини антиген-индуцированной контрактуры гладких мыши изолированной трахеи морской свинки использовали животных обоего пола массой 400500 г. Животных забивали, извлекали трахею, очищали ее и разрезали на кольца по 2 хряща в каждом кольце. Полученные кольца (4-5) соединяли в цепочку и помещали в термостатируемую при $37^{\circ} \mathrm{C}$ ванночку объемом 15 мл, содержащую раствор Кребса-Хенсляйта (118,4 mM $\mathrm{NaCl}, 4,7 \mathrm{mM} \mathrm{KCl}, 2,5 \mathrm{mM} \mathrm{CaCl}_{2}, 1,2 \mathrm{mM} \mathrm{MgSO}_{4}$, 25,0 mM NaHCO $3,1,2$ mM KH${ }_{2} \mathrm{PO}_{4}, 10$ mМ глюкоза, $\mathrm{pH}=7,4)$. Исследование релаксирующей активности проводили в изотоническом режиме, исходная нагрузка на препарат составляла 0,7-1 г. В качестве датчика, преобразующего механический сигнал в электрический, использовали отечественный прибор механотрон $6 \mathrm{M} * 2$ Б, соединенный с самописцем КСП-4. Сокрашения гладкомышечного препарата (ГМП) вызывали добавлением в среду инкубации гистамина (Sigma) или ацетилхолина (Sigma) в концентрации $10^{-8}-10^{-9} \mathrm{M}$. Через $30-60$ с регистрировали максимальную амплитуду сокращения гладких мышц. После того, как амплитуда достигала плато, в ванночку добавляли ФП в дозах 100 мкг/мл, 200 мкг/мл, 400 мкг/мл. Эффект исследуемых веществ оценивали по степени расслабления ГМП трахеи и выражали в процентах относительно амплитуды максимального сокращения гладких мышц. Определяли среднюю величину степени расслабления от измерения 3 отрезков трахеи.

Для воспроизведения модели антиген-индуцированной контрактуры гладких мыши изолированной трахеи, морских свинок массой 250-300 г иммунизировали по методу Р. Andersson [7]. Животным однократно вводили смесь антигена (АГ) с адъювантом - 10 мкг овальбумина (OA) (Sigma) и 100 мг гидроокиси аллюминия $\left(\mathrm{Al}(\mathrm{OH})_{3}\right)$ на свинку. Период иммунизации продолжался 30 дней, после чего животных забивали, извлекали трахею и готовили ГМП по методу, описанному выше. Контрактуру вызывали добавлением в среду инкубации ОА в концентрации 1 мкг/мл. Величину индуцированной овальбумином контрактуры сравнивали с величиной сокращения, вызванного гистамином $\left(10^{-5} \mathrm{M}\right)$. Эффект ФП оценивали по степени расслабления ГМП трахеи и выражали в процентах относительно амплитуды максимального сокращения гладких мышц, вызванного ОА.

\section{Результаты}

\section{Влияние ФП на активность 5-лПГ и 15-лПГ}

ФП оказывал выраженное ингибирующее действие на активность 5-липоксигеназы нейтрофилов периферической крови здоровых доноров. Так, в суспензионной культуре достоверный ингибирующий эффект препарата, оцениваемый по продукции лейкотриенов отмечался при концентрации уже 5 мкг/мл; при концентрации 100 мкг/мл активность фермента подавлялась практически полностью. В клетках, культивируемых на коллагеновой подложке, достоверный ингибирующий эффект также отмечали при концентрации ФП 5 мкг/мл; при концентрации 20 мкг/мл активность 5-ЛПГ снижалась примерно в 20 раз. Таким образом, ФП подавляет синтез лейкотриенов, уменьшая количество доступного для 5-ЛПГ субстрата (табл. 1).

При изучении воздействия ФП на активность 15-ЛПГ было установлено, что при концентрации ФП 80 мкг/мл активность фермента падала в 2 раза. Увеличение концентрации ППФ до 
ТАБЛИЦА 1. ПОДАВЛЕНИЕ АКТИВНОСТИ ФЕРМЕНТОВ 5-ЛИПОКСИГЕНАЗА И 15-ЛИПОКСИГЕНАЗА ПОД ДЕЙСТВИЕМ ФП

\begin{tabular}{|c|c|c|c|}
\hline \multicolumn{2}{|c|}{ 5-липоксигеназа } & \multicolumn{2}{|c|}{ 15-липоксигеназа } \\
\hline $\begin{array}{c}\text { Доза ФП } \\
\text { (мкг/мл) }\end{array}$ & $\begin{array}{c}\text { Активность } \\
\text { 5-лПг (\% исх.) }\end{array}$ & $\begin{array}{c}\text { Доза ФП } \\
\text { (мкг/мл) }\end{array}$ & $\begin{array}{c}\text { Активность } \\
\text { 5-лПг (\% исх.) }\end{array}$ \\
\hline 5 & 70 & 25 & 90 \\
\hline 10 & 30 & 50 & 80 \\
\hline 25 & 0 & 100 & 42 \\
\hline 100 & 0 & 200 & 20 \\
\hline
\end{tabular}

250 мкг/мл приводило к 5-кратному угнетению активности 15-ЛПГ (табл. 1). Таким образом, ФП растительного происхождения являются активными ингибиторами обеих липоксигеназ.

\section{Изучение противовоспалительной активности ФП на модели отека лап крысы}

Для изучения противовоспалительных эффектов ФП были использованы традиционные модели острого экссудативного воспаления отеки лап крыс, индуцированные каррагинаном и ПАФ. Результаты представлены в табл. 2.

Как следует из представленных данных, на модели каррагинан-индуцированного отека ФП оказывает противовоспалительное действие, которое по степени выраженности уступает эффекту индометацина - препарата сравнения. Аналогичный эффект выявлен и на модели ПАФ-индуцированного отека.

\section{Изучение бронхолитического действия ФП}

Установлено (рис.), что на модели гистамининдуцированной контрактуры ГМП трахеи морской свинки ФП проявляет выраженную бронхолитическую активность в дозах 100 мкг/мл и 200 мкг/мл - торможение сокращения составило 55,6 и 40,8\% соответственно. Аналогичным образом, ФП в дозе 200 мкг/мл вызывал значительное $(67,3 \%)$ торможение сокращения, индуцированного ацетилхолином (рис.). Выраженная бронхопротективная активность на данной модели наблюдалась также в дозе 100 мкг/мл - торможение составило 57,1\%.

При изучении активности ФП вещества на модели антиген-индуцированной контрактуры ГМП трахеи незначительное торможение сокращения отмечали только в дозе 100 мкг/мл $22,3 \%$, что говорит об умеренно выраженной бронхолитической (антианафилактической) активности. В других дозах на данной модели бронхолитическое действие не выявлено (рис.). Таким образом, на моделях бронхоспазма in vitro на морских свинках наиболее выраженной бронхолитической активностью ФП обладает в дозе 100 мкг/мл.

\section{Обсуждение}

Исследования последних лет свидетельствуют о том, что оптимальная профилактика и лечение бронхиальной астмы, воспалительных заболеваний и многих других патологических состояний достигается с помощью безопасных природных соединений, обладающих, в частности, антиоксидантными свойствами и/или способностью к ингибиции липоксигеназы. Для лечения бронхиальной астмы применяются, в основном, две группы препаратов: это бронходилататоры, которые уменьшают спазм бронхов, и противовоспалительные средства, которые уменьшают гиперемию, отечность бронхов, однако для купирования внезапно развившегося приступа астмы последние не годятся.

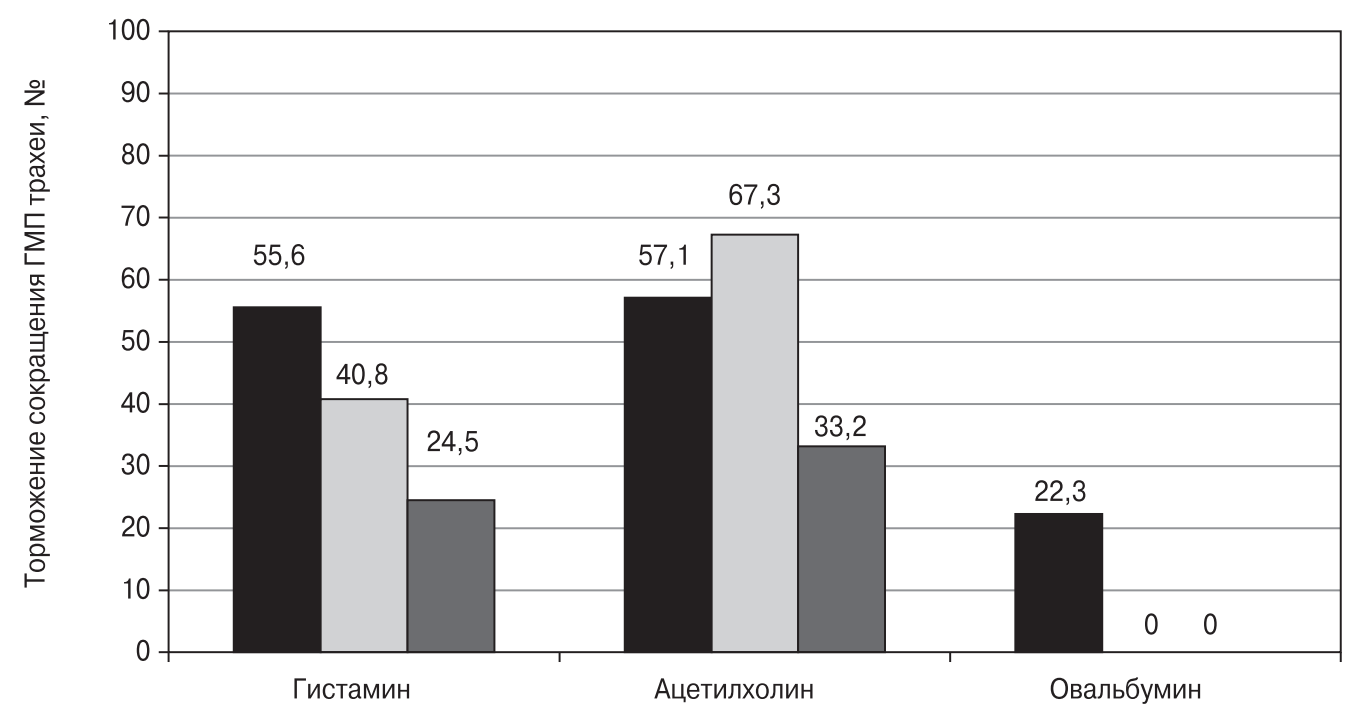

Индукторы сокращения ГМП трахеи

100 мкг/мл

200 мкг/мл

400 мкг/мл

Рисунок. Бронхолитическая активность ХС на моделях бронхоспазма in vitro 


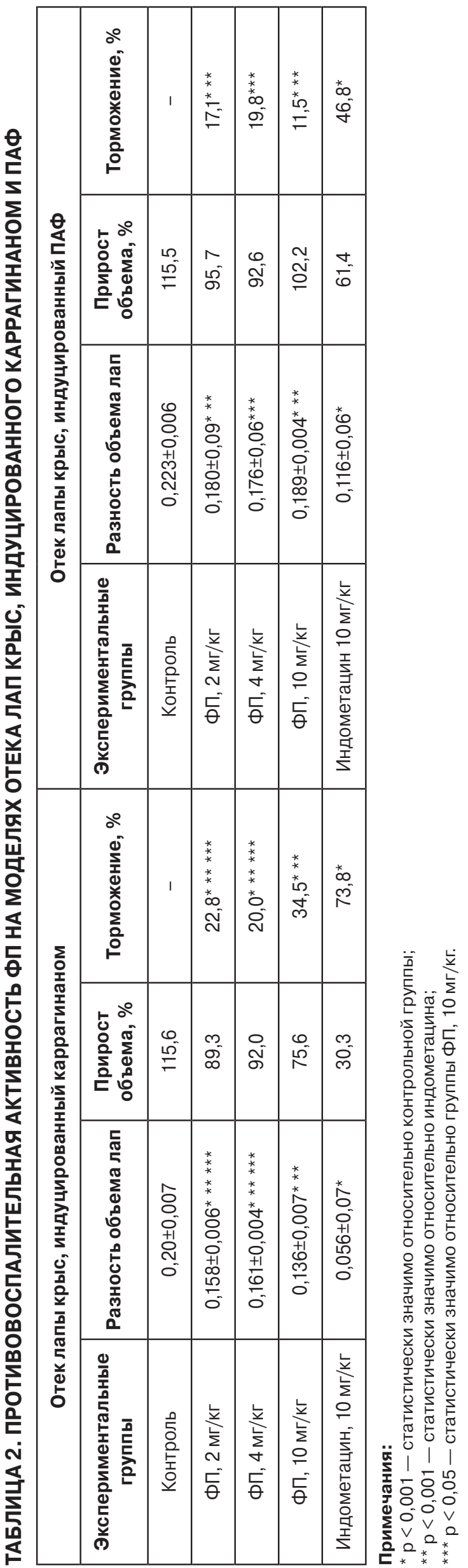

Липоксигеназный путь метаболизма арахидоновой кислоты приводит к образованию лейкотриенов, липоксинов и других биологически активных веществ с выраженным вазоконстрикторным, аритмогенным и хемоаттрактантным действием.

Фермент 5-ЛПГ катализирует первые два шага метаболизма арахидоновой кислоты в лейкотриены, играющие важнейшую роль в патофизиологии бронхиальной астмы, воспалительных заболеваний кишечника, ревматоидного артрита, муковисцидоза, псориаза и аллергического ринита. Получены убедительные доказательства эффективности специфической терапии перечисленных заболеваний с помощью ингибиторов ЛПГ. Липоксины (LXA и LXB) - это тригидроксикислоты, полученные из арахидоновой кислоты в результате последовательного действия двух липоксигеназ - 15-ЛПГ и 5-ЛПГ. Установлено, что липоксины регулируют клеточные реакции воспаления и иммунитета.

В связи с этим поиск новых, эффективных и безопасных ингибиторов ЛПГ остается весьма актуальным. Обнаруженная способность ФП ингибировать активность 5-ЛПГ и 15-ЛПГ (табл. 1) свидетельствует о способности ФП подавлять синтез как лейкотриенов, так и липоксинов. Лейкотриены играют важную роль в патогенезе бронхиальной астмы - они способствуют сокращению гладкой мускулатуры дыхательных путей, повышению проницаемости сосудов, активации воспалительных клеток, высвобождающих вторичные медиаторы воспаления. С другой стороны, важным компонентом устранения приступов бронхиальной астмы являются вешества с бронхолитическими свойствами, способные устранять бронхоспазм. В этой связи, представляется особенно важным, что ФП проявляют не только противовоспалительные свойства, подтвержденные на ряде моделей (табл. 1 и 2), но также - бронхолитическую активность (рис.). Ведь большинство классическихбронходилататоров (например, $\beta 2$-адреностимуляторы и антихолинергические средства), быстро устраняют мышечный спазм бронхов, однако не влияют на лежащее в основе бронхиальной астмы воспаление.

Полученные данные хорошо сочетаются с ранее выявленной способностью ФП выступать в качестве физиологического контррегулятора MIF (фактора ингибиции миграции макрофагов) - важнейшего провоспалительного цитокина, играющего ведущую роль в патогенезе системного воспалительного ответа и сепсиса [6]. Показано, что при экспериментальных инфекциях, вызванных вирусом клещевого энцефалита и вирусом простого герпеса, ФП выступал в качестве антагониста MIF [2, 4]. Аналогичным образом можно трактовать данные по терапевтической активности ФП на модели токсического шока, вызванного у мышей альфа-токсином 
Staphylococcus aureus [1], поскольку известно, что ключевым медиатором системы естественной резистентности организма при септическом шоке, а также ответе на стафилококковый и стрептококковый экзотоксины является MIF.

Таким образом, обнаруженные новые свойства ФП могут быть использованы при разработке принципиально новых препаратов для профилактики и лечения бронхиальной астмы, воспалительных заболеваний и иных патологических состояний.

\section{Список литературы}

1. Зайцева Л.Г., Бехало В.А., Васильев И.К., Годунов Р.С., Киреева И.В., Кожевникова Т.Н., Нагурская Е.В., Наровлянский А.Н., Ожерелков С.В., Пронин А.В., Санин А.В. Коррекция функциональной активности перитонеальных макрофагов мышей фоспренилом и гамавитом при введении высоких доз альфа-токсина Staphylococcus aureus // ЖМЭИ. - 2005. - № 6. - С. 51-57.

2. Кожевникова Т.Н., Ожерелков С.В., Зварцев Р.В., Санина В.Ю., Амченкова А.М., Наровлянский А.Н., Пронин А.В., Санин А.В. Изучение роли фактора ингибиции миграции макрофагов (MIF) при экспериментальной флавивирусной инфекции у мышей // Материалы Объединен. иммунол. форума. СПб. 30 июня - 5 июля 2008; Рос. иммунол. журн. - 2008. - Т. 2 (11), № 2-3. - С. 250.

3. Нестерова Ю.В., Поветьева Т.Н., Аксиненко С.Г., Суслов Н.И., Гайдамович Н.Н., Нагорняк Ю.Г.,
Попова Е.В., Кравцова С.С., Андреева Т.И. Исследование противовоспалительной активности экстрактов, полученных из растений Сибири // Вестн. РАМН. - 2009. - № 11. - С. 30-34.

4. Ожерелков С.В., Зварцев Р.В., Саличев А.В., Суслов А.П., Кожевникова Т.Н., Наровлянский А.Н., Пронин А.В., Санин А.В. Исследование динамики стимуляции мРНК миграции ингибирующего фактора при экспериментальной герпетической инфекции и на фоне введения полипренолсодержащего иммуномодулятора у мышей // Цитокины и воспаление. - 2010. Т. 9, № 3. - С. 49.

5. Санин А.В., Наровлянский А.Н., Ожерелков С.В., Пронин А.В., Санина В.Ю. Иммуномодуляторы в ветеринарной практике - применение и противоречия // Ветеринарная клиника. - 2008. № $10-12$.

6. Суслов А.П., Коноплева М.В., Третьяков О.Ю., Кожушный А.П. Роль фактора подавления миграции макрофагов в формировании системного воспалительного ответа и развития сепсиса // ЖМЭИ. - 2008. - № 5. - С. 15-23.

7. Anderson P. Antigen-induced bronchial anaphilaxis in actively sensitized geinea-pigs // Allergy. — 1980. Vol. 35. - P. 63-71.

8. Simon A., Najid A., Chulia A.J., Delage C., Rigaud M. Inhibition of lipoxygenase and of human leukemic HL60 cells proliferation by ursolic acid isolated from heather flowers (Calluna vulgaris) // Biochim. Biophys. Acta. - 1992. - Vol. 1125, N 1. - P. 72-86. 